Published in final edited form as:

Curr Diab Rep. 2014 September ; 14(9): 519. doi:10.1007/s11892-014-0519-8.

\title{
Metabolic Abnormalities in the Pathogenesis of Type 1 Diabetes
}

\author{
Shuyao Zheng and Clayton E. Mathews* \\ Department of Pathology, Immunology, and Laboratory Medicine, University of Florida, \\ Gainesville, FL 32610-0275
}

\begin{abstract}
Clinical onset of Type 1 Diabetes (T1D) is thought to result from a combination of overt beta cell loss and beta cell dysfunction. However, our understanding of how beta cell metabolic abnormalities arise during the pathogenesis of disease remains incomplete. Despite extensive research on the autoimmune nature of T1D, questions remain regarding the time frame and nature of beta cell destruction and dysfunction. This review focuses on the characterizations of beta cell dysfunction in the pre-diabetic and T1D human and mouse model. Studies have shown evidence supporting progressive loss of beta cell mass and function prior to T1D onset, while other scientists argue beta cell destruction occurs later in the disease process. Determining the time frame of beta cell destruction and identifying metabolic mechanisms that drive beta cell dysfunction has high potential for successful interventions to maintain insulin secretion for individuals with established T1D as well as those with pre-diabetes.
\end{abstract}

\section{Keywords}

Type 1 Diabetes; Insulin Secretion; Beta Cell Dysfunction; Pre-Diabetes; NOD Mice; Human; Metabolic Abnormalities

\section{INTRODUCTION}

Hyperglycemia and insulinopenia are hallmark clinical phenotypes associated with Type 1 Diabetes (T1D). A reduction in the capacity to secrete insulin in response to macronutrients precedes the onset of T1D in most cases. As T1D is classically considered an autoimmune disease, the loss of function has been declared to occur as a result of beta cell loss.

Histological evidence supports such a notion as both islet number and insulin positive area are reduced or absent in almost all postmortem samples taken from individuals diagnosed with T1D, even those with a recent onset. Even prior to diagnosis, loss of beta cells may be occurring but silently. Accordingly, loss of function can only be detected using longitudinal

Contact information for Shuyao Zheng: 1275 Center Dr, Room J522, Gainesville, FL 32610-0275 Phone: 352-273-9301 szhang1230@ufl.edu. “Correspondence to: Department of Pathology, Immunology, and Laboratory Medicine The University of Florida College of Medicine University of Florida 1275 Center Dr, Room J597, Gainesville, FL 32610-0275 Phone: 352-273-9269 clayton.mathews@pathology.ufl.edu.

Compliance with Ethics Guidelines

Conflict of Interest Shuyao Zheng and Clayton E. Mathews declare that they have no conflict of interest.

Human and Animal Rights and Informed Consent This article does not contain any studies with human or animal subjects performed by any of the authors. 
metabolic tests, such as mixed-meal or glucose tolerance tests. Residual beta cell function persists in most patients subsequent to diagnosis, however erosion of insulin release continues until it falls below detectable levels in most patients. Not only is the loss of mass and function "silent", but also data at this time have yet to emerge that link loss of function with loss of mass.

In the past four decades, we have made enormous progress in diagnostic techniques and treatment strategies based on our knowledge of genetic susceptibility and the use of autoantibodies as immunologic biomarkers [1-3]. Yet despite our increased understanding of the autoimmune nature of T1D, multiple questions remain regarding the exact nature and extent of beta cell destruction and dysfunction in T1D. While it is widely accepted that loss of insulin secretion occurs at least in part, due to beta cell death, we have a limited understanding of the metabolic abnormalities prior to beta cell destruction and during the progression of islet autoimmunity towards overt T1D. Little is known about the magnitude and significance of residual insulin production and beta cell function [4; 5]. Moreover, there is still controversy over the time frame of beta cell loss during the disease progression towards clinical diagnosis. Identifying metabolic mechanisms and predictors that drive beta cell dysfunction has high potential to influence the administration of interventions to maintain insulin secretion for individuals with established T1D as well as those with prediabetes. Here we discuss the current state of the art as well as identify major unknowns/ challenges that must be met to better understand metabolic changes that occur prior to diagnosis of T1D.

\section{T1D IN HUMANS}

\section{CHARACTERIZATION OF BETA CELL FUNCTION BEFORE T1D DIAGNOSIS}

Autoantibodies against beta cell autoantigens are indicators that mark the loss of selftolerance and can indicate an early stage in the progression, or potential to progress to T1D. Metabolic measures, such as changes in circulating C-peptide [6] or the degree of changes in first phase insulin release (FPIR) [7; 8], allow for additional levels of risk for T1D to be assessed. Studies on the natural history of T1D have demonstrated that a progressive loss of FPIR in autoantibody positive $\left(\mathrm{AAb}^{+}\right)$individuals represents a late stage in the period prior to diagnosis [9-17]. Further, a preservation of FPIR has been linked to failure to progress to T1D [6]. Early cross-sectional studies by Lo, et al. [18] have shown the occurrence of a temporal association between the presence of islet cell antibodies and a progressive decline in first phase inulin response (FPIR) to intravenous glucose tests (IVGTT) in what is known as the "pre-diabetic phase". A majority of studies have reported that the loss of FPIR is most pronounced in response to glucose in early "pre-diabetes" in comparison to other stimuli [12-14], pointing to a phase of $\beta$ cell dysfunction well before diagnosis.

Results published to date have demonstrated that a differential sensitivity to secretagogues exists with those progressing to T1D becoming "blind" to glucose before responses to other secretagogues are lost [13; 14]. Survival analysis by Barker, et al. [19] found that higher quartiles of 2-hour glucose and lower quartiles of FPIR at baseline were associated with decreased diabetes-free survival. Abnormal IVGTTs and/or abnormal oral glucose tolerance tests (OGTT) before the development of diabetes suggests altered glucose to insulin dose- 
response relationship and loss of maximum insulin secretory response to glucose before disease onset. On the other hand, acute insulin response to arginine appears to be less altered with time, and increased basal glycemia remained substantial even at the onset of the disease [20]. This reinforces the supposition that even the pre-diabetic state may be associated with a glucose-specific beta cell functional abnormality in addition to a decreasing beta cell mass.

Loss of FPIR in response to glucose but not other secretagogues (Arginine, Tolbutamide, Glucagon) would result from processes restricted to glucose, such as glucose transport and metabolism, but not shared mechanism (i.e. insulin production, ATP generation, or potassium channel activity). Studies using isolated islets from T1D patients have been limited but the published work supports the validity of this idea [21;22]. Immediately after isolation, islets from T1D patients lacked glucose stimulated insulin secretion (GSIS). The loss of GSIS was not linked to lower levels of insulin gene expression, but instead with a reduction in the level of mRNA for glucokinase and other members of the glycolysis pathway when compared to islets isolated from individuals without T1D [21]**. Interestingly, the islets isolated from patients with T1D also had heightened inflammation compared to controls [21]. However, GSIS was recovered and inflammatory signals lost over the course of a 3-week culture [21;22]. The data from long-term islet culture suggest that the change in environment, from in vivo to in vitro, can induce $\beta$ cell recovery. However these data were generated from the islets of individuals diagnosed with T1D and it will take a similar effort studying islets from organ donors that are positive for T1D-relevant autoantibodies to begin to address the mechanism of beta cell dysfunction prior to onset of disease. Nonetheless, the correlation has provided clues to further investigate how inflammation leads to loss of GCK in insulin positive islets from individuals with established T1D.

\section{RESIDUAL BETA CELL MASS}

The commonly held view is that T1D develops due to the establishment of a non-tolerogenic immune system and that beta cells fail as the result of autoimmune-mediated destruction. Spurred by findings in the Non Obese Diabetic (NOD) and Biobreeding Diabetes-Prone (BB-DP) murine models, the perception is that the destruction continues until the insulin producing cells have been eliminated [23] and basal as well as stimulated c-peptide levels are undetectable. Recent publications have refuted this notion, by demonstrating that a significant number of patients with long-standing type 1 diabetes maintain both basal and stimulated c-peptide [4;24-27], albeit reduced compared to the levels routinely measured in healthy controls. Quite striking was the prevalence of this phenotype in individuals with T1D, with these three studies reporting persistent c-peptide in $38 \%[25]^{* *}, 85 \%$ [26]**, and $67 \%$ [24] of the patients enrolled. A fourth and even more recent study using an insulin assay with very high sensitivity reported that MMTT-stimulated serum C-peptide was detectable at very low levels (>3.3 pmol/1) in 54 of 74 (73\%) individuals with long-standing T1D [28]*. The increase in stimulated c-peptide challenges the belief that complete beta cell destruction is an inevitable consequence of disease progression, and indicates the presence of at least a small population of surviving beta cells. The presence of such a beta cell mass in patients with long-standing diabetes is intriguing as the potential exists for these cells to be therapeutically manipulated if the mechanism of reduced function can be elucidated. 


\section{BETA CELL FUNCTION AFTER DIAGNOSIS OF T1D}

The JDRF nPOD [Network for Pancreatic Organ Donors with Diabetes] [29] is a biorepository that collects pancreata from organ donors with T1D, organ donors that are positive for T1D-related autoantibodies, as well as age and sex matched controls. The nPOD project affords access to a unique sample set and allows investigators the ability to perform novel studies and to make observations and test postulates on the pathogenesis of T1D in human specimens that would otherwise be inaccessible. In the nPOD biorepository there are 100 pancreata from individuals diagnosed with T1D. Of this, 34 of the donated pancreata from patients with T1D had insulin positive islets, although in most of these cases the number of islets is significantly reduced. The cases with T1D and insulin positive islets had a later age of onset $(15.4 \pm 9.6$ years versus $11.8 \pm 8.3 ; \mathrm{p}=0.003$; Mean $\pm \mathrm{SD})$ and shorter duration of disease $(12.0 \pm 15.7$ years versus $23.8 \pm 18.8$; $\mathrm{p}=0.04$; Mean $\pm \mathrm{SD})$ [Figure 1]. This suggests that insulin positive $\beta$ cells are present in approximately $1 / 3$ of the patients with T1D, yet they are dysfunctional.

Further support of impaired beta cell function despite potential residual beta cell mass can be seen from Steele, et al.'s [30] study that demonstrated approximately $30-40 \%$ of the patients with established T1D exhibited secretion of insulin in response to a MMTT, yet these individuals remained hyperglycemic. The team also found that the pattern of insulin secretory response within the first 6 months after diagnosis of diabetes is a significant predictor of the rate of loss of insulin secretion. Sherr et al. [31] showed significant decline in insulin secretory response to MMTT's in human subjects with T1D with early insulin response compared to those with late response. Meal stimulated insulin secretory responses were still seen in those with long standing T1D and detectable c-peptide, which lends further evidence that there may be intrinsic metabolic differences in beta cells in those individuals who retain beta cell function compared to those who do not.

Currently, all data comparing whole body metabolism to histology or function of isolated islet are corollary, as these data do not originate from samples taken from the same individual. Direct data from these categories could only be collected by an effort similar to the DiViD study [32] that would also include metabolic measurements, which is unlikely due to the complications and termination of that protocol [33]. Therefore, a great benefit may come from experimental plans that include cross-talk between human clinical and basic science methodologies with the use of animal models for completion of invasive studies.

\section{NOD MOUSE MODEL}

Cross-sectional studies in humans have shown significant metabolic dysfunction during the pre-diabetes period that worsen during progression of T1D, yet there are limitations for longitudinal and more invasive time course studies. For more involved experiments an animal model could be used, provided that it is a surrogate that reflects the changes observed during pathogenesis of human T1D. The Non-obese diabetic (NOD) mouse strain has been widely used for research to unravel the genetics of T1D as well as the immunological mechanisms of T1D. NOD mice have a significant number of genetic and immunologic traits that are shared or have high homology with the human disease [34].. NOD mice have very aggressive form of autoimmune diabetes. Insulitis develops around 4 weeks of age and 
leads to beta cell dysfunction and destruction resulting in overt hyperglycemia in $\sim 80 \%$ of female and $20 \%$ of male NOD mice by 30 weeks of age.

\section{NOD CHARACTERIZATION OF BETA CELL MASS}

Although data indicating a progressive decline in insulin response preceding overt hyperglycemia appears to be well received $[7 ; 18-20 ; 30 ; 35]$, the time course of beta cell failure and destruction remains controversial for human T1D and requires further clarification in the NOD model of T1D. One commonly held view is that there is a gradual and progressive decline in beta cell mass and function that begins shortly before overt onset of disease. Sreenan et al. [8] measured beta cell mass and rates of beta cell proliferation as well as insulin secretory responses from the perfused pancreas in NOD and control mice 89,13 , and 18 weeks of age and found that beta cell mass was significantly reduced by $42 \%$ in 13-week-old non-diabetic NOD mice, and by $73 \%$ in 18 -week-old diabetic NOD mice. Additionally, at 18 weeks of age diabetic NOD mice exhibited a reduced insulin secretory response to a greater degree than loss of beta cell mass. After adjusting for confounding factors (i.e. whether the reduction in insulin secretion in non-diabetic NOD mice was only due to the reduction in beta cell mass), insulin secretory response to increased glucose and to arginine was still significantly reduced at the 18 -week time point, pointing to evidence of beta cell dysfunction in addition to reduced mass. These data give strong quantitative evidence that beta cell mass and function progressively fall before onset of T1D.

Yet an opposing view portends that beta cell mass does not begin to fall until the onset of type 1 diabetes. Shimada et al. [36] found a correlation between cytokine profiles with either their pathogenic or protective roles in NOD mice, and observed a sudden shift in cytokine phenotype from Th2 to Th1 at the onset of hyperglycemia in NOD mice. Preliminary histology of these mice revealed approximately 20-30 insulin-positive islets per slide for the non-diabetic NOD mice compared to only ten or less insulin-positive islets per slide in those that had developed hyperglycemia. Other studies have shown promising results of durable remission in adult female NOD mice after either anti-thymocyte globulin or anti-CD3 treatment within the first 2-3 days after the onset of overt diabetes $[37 ; 38]$. These data suggest that diabetes in the NOD mouse may progress predominantly as inflammatory beta cell dysfunction without actual beta cell destruction until later in the autoimmune disease process. In line with these studies, Sever et al. [39] shows that beta cell mass moderately reduced with age, with significant decrease in bioluminescent imaging (BLI) of NOD transgenic mice expressing luciferase gene under control of insulin promoters, indicating a loss of beta cell function, but not necessarily mass, with age and duration of diseases.

\section{IMPAIRED FIRST-PHASE INSULIN RESPONSE TO GLUCOSE IN NOD}

While there has been considerable progress in understanding the natural history of beta cell decline in patients at risk for T1D development, very little is known regarding the changes in beta cell function or mass prior to diabetes onset in the NOD mouse. In the NOD mouse, diabetes is preceded by a preclinical phase in which autoimmune insulitis is associated with persistence of normal fasting blood glucose concentrations. Similar to what has been reported in human beings, a significant decrease in FPIR during an intraperitoneal glucose tolerance test has been observed in NOD mice despite maintenance of glucose tolerance 
during the pre-diabetic period [7]. Previously, Reddy and colleague demonstrated a decrease in FPIR in vivo when comparing female NOD mice at 6 weeks and a second cohort at 21 weeks of age [40]. Two additional groups reported reductions in FPIR by pancreas perfusion between 23 and 32, as well as 8 and 18 weeks of age, respectively [7; 8]. These data highlight the fact that as disease progresses, the degree of insulitis appears to be associated with increased fasting glucose and further loss of GSIS, indicating that a defect in FPIR may be an initial indicator of beta cell damage. However, these were all single point measures per mouse and did not demonstrate the progression of $\beta$ cell failure serially in individual mice.

We have recently observed, using sequential glucose tolerance tests, that female NOD mice exhibit a steady increase in blood glucose levels which was associated with a progressive decline of FPIR to glucose before onset of diabetes [35]**. Additionally, loss of first-phase insulin response to glucose precedes any measurable defect in insulin secretion in response to L-arginine stimulation. These results indicate that the initial sign of beta cell damage in NOD mice is a defect of the first phase of glucose-induced insulin secretion, which is followed by a total loss of the ability to respond to glucose or arginine stimulation. Analogous to findings in human disease progression, the impairment of first phase of glucose-induced insulin secretion could be an early in vivo marker of progressive beta cell failure in NOD mice. As these measurements are similar to those reported in human T1D, studies that elucidate the mechanisms that underlie the loss of glucose responsiveness in NOD islets are likely to generate results that are relevant to the human disease.

\section{NOD MARKERS OF BETA CELL DYSFUNCTION}

In addition to using pancreatic islet autoantibodies and genetic screening [41] as means for predicting T1D, we are now finding promising results for new metabolic predictors. Early indicators of T1D progression in humans are consequent from aforementioned studies showing loss of first-phase insulin response to glucose during MMTT's, and findings that preserved C-peptide production in nonprogressors to clinical T1D may help determine response to preventative and diagnostic efforts [6].

Whether due to intrinsic beta cell dysfunction or exposure to cytokines secreted during the autoimmune attack, these metabolic abnormalities may ultimately a result in mitochondrial damage and dysfunction. Mitochondria are essential for GSIS as these organelles mediate the glucose-induced rise in cellular ATP that closes the K-ATP channels leading to insulin secretion and the downstream maintenance of normal blood glucose levels. Sever et al. [39] found that the decreased light emission in Bioluminescence Imaging (BLI) (under the control of insulin promoters) in beta cells from older diabetic NOD mice resulted from the combined effects of reduced beta cell mass, a fall in luciferase mRNA and protein levels, as well as decreased intracellular ATP concentrations. These correlative studies demonstrate the promise for applications of BLI to be used as a noninvasive and more sensitive method for in vivo detection and tracking of early metabolic changes as indicators of early beta cell dysfunction. By further studying differences in mitochondrial protein expression or function in tissues from NOD mice or individuals with and without T1D, we may better predict disease progression and explain why T1D patients fail to secrete insulin despite the persistence of beta cell mass. 


\section{CONCLUSION AND DISCUSSION}

Individuals with 2 or more $\mathrm{AAb}$, intact FPIR, and normal glucose tolerance have a 30-50\% risk of developing diabetes over a 5 year period. When glucose tolerance becomes abnormal, the risk increases to 70-90\% over 5 years. Long-term, clinical studies have defined secretagogue responses in patients with long-standing T1D. Patients with long-standing T1D ( 40\%) maintain both basal and stimulated c-peptide in an MMTT [24-26; 28] albeit reduced compared to levels routinely measured in healthy controls. The similarities in beta cell dysfunction between autoantibody positive individuals and those with established T1D suggest a common mechanism for beta cell failure in most individuals that progress to T1D. However, there remains a need to establish the mechanisms of beta cell dysfunction in these two groups.

Future studies should aim at developing new strategies for the in vivo imaging and measuring of pancreatic beta cell mass and function, as clinical and investigational tools for detecting and monitoring the processes leading to clinical phenotypes of T1D. After identiying components of the glucose sensing and insulin secretory machinery pathways that are altered, we could then study high-risk nondiabetic subjects (using MMTT and other insulin secretagogues) to correlate these components with progression and slow or nonprogression to T1D. The NOD mouse model should provide excellent support for these studies due to the similarities in metabolic dysfunction that occur in the mouse and individuals that progress to T1D. NOD mice could be used for longitudinal studies analyst more closely examine disease progression.

Ultimately, understanding metabolic processes in the pathogenesis of disease can better delineate the timeline of beta cell destruction and dysfunction in NOD mice and human models of disease. This additional knowledge should have a major impact on how T1D is treated, as this could provide a means to prevent T1D prior to diagnosis in those identified as highest risk or for reviving residual beta cell function resulting in insulin-free status in a significant number of patients [24-26;28]. The presence of the dysfunctional beta cell mass in these patients [Figure 1] should provide hope that through therapeutic manipulation, the mechanisms causing impaired function could be reversed and in conjunction with immunotherapy to restore immune tolerance to beta cells disease remission could be attained.

\section{Acknowledgments}

Supported by research grants R01 DK074656 and U01 AI042288 from the National Institutes of Health as well as from the Juvenile Diabetes Research Foundation, the American Diabetes Association, and The Leona M. and Harry B. Helmsley Charitable Trust. Support from the Network for Pancreatic Organ Donors with Diabetes (nPOD), a collaborative type 1 diabetes research project sponsored by JDRF was essential for completion of this work. The resources provided by the partnership of Organ Procurement Organizations (OPO) with nPOD are listed at http:// www.jdrfnpod.org/for-partners/npod-partners/.

\section{REFERENCES}

1. Miersch S, Bian X, Wallstrom G, Sibani S, Logvinenko T, Wasserfall CH, Schatz D, Atkinson M, Qiu J, LaBaer J. Serological autoantibody profiling of type 1 diabetes by protein arrays. Journal of proteomics. 2013; 94:486-496. [PubMed: 24148850] 
2. Stankov K, Benc D, Draskovic D. Genetic and epigenetic factors in etiology of diabetes mellitus type 1. Pediatrics. 2013; 132:1112-1122. [PubMed: 24190679]

3. Anagandula M, Richardson SJ, Oberste MS, Sioofy-Khojine AB, Hyoty H, Morgan NG, Korsgren O, Frisk G. Infection of human islets of langerhans with two strains of coxsackie B virus serotype 1: Assessment of virus replication, degree of cell death and induction of genes involved in the innate immunity pathway. Journal of medical virology. 2013

4. Vanbuecken DE, Greenbaum CJ. Residual C-peptide in type 1 diabetes: what do we really know? Pediatric diabetes. 2014; 15:84-90. [PubMed: 24645775]

5. Pietropaolo M. Persistent C-peptide: what does it mean? Current opinion in endocrinology, diabetes, and obesity. 2013; 20:279-284.

6. Schatz D, Cuthbertson D, Atkinson M, Salzler MC, Winter W, Muir A, Silverstein J, Cook R, Maclaren N, She JX, Greenbaum C, Krischer J. Preservation of C-peptide secretion in subjects at high risk of developing type 1 diabetes mellitus--a new surrogate measure of non-progression? Pediatric diabetes. 2004; 5:72-79. [PubMed: 15189492]

7. Kano Y, Kanatsuna T, Nakamura N, Kitagawa Y, Mori H, Kajiyama S, Nakano K, Kondo M. Defect of the first-phase insulin secretion to glucose stimulation in the perfused pancreas of the nonobese diabetic (NOD) mouse. Diabetes. 1986; 35:486-490. [PubMed: 3514327]

8. Sreenan S, Pick AJ, Levisetti M, Baldwin AC, Pugh W, Polonsky KS. Increased beta-cell proliferation and reduced mass before diabetes onset in the nonobese diabetic mouse. Diabetes. 1999; 48:989-996. [PubMed: 10331402]

9. Soeldner JS, Tuttleman M, Srikanta S, Ganda OP, Eisenbarth GS. Insulin-dependent diabetes mellitus and autoimmunity: islet-cell autoantibodies, insulin autoantibodies, and beta-cell failure. The New England journal of medicine. 1985; 313:893-894. [PubMed: 3897867]

10. Eisenbarth GS, Srikanta S, Fleischnick E, Ganda OP, Jackson RA, Brink SJ, Soeldner JS, Yunis EJ, Alper C. Progressive autoimmune beta cell insufficiency: occurrence in the absence of highrisk HLA alleles DR3, DR4. Diabetes Care. 1985; 8:477-480. [PubMed: 3876922]

11. Srikanta S, Ganda OP, Rabizadeh A, Soeldner JS, Eisenbarth GS. First-degree relatives of patients with type I diabetes mellitus. Islet-cell antibodies and abnormal insulin secretion. N Engl J Med. $1985 ; 313: 461-464$.

12. Srikanta S, Ganda OP, Gleason RE, Jackson RA, Soeldner JS, Eisenbarth GS. Pre-type I diabetes. Linear loss of beta cell response to intravenous glucose. Diabetes. 1984; 33:717-720.

13. Srikanta S, Ganda OP, Jackson RA, Brink SJ, Fleischnick E, Yunis E, Alper C, Soeldner JS, Eisenbarth GS. Pre-type 1 (insulin-dependent) diabetes: common endocrinological course despite immunological and immunogenetic heterogeneity. Diabetologia. 1984; 27(Suppl):146-148. [PubMed: 6383919]

14. Ganda OP, Srikanta S, Brink SJ, Morris MA, Gleason RE, Soeldner JS, Eisenbarth GS. Differential sensitivity to beta-cell secretagogues in "early," type I diabetes mellitus. Diabetes. 1984; 33:516-521. [PubMed: 6373458]

15. Srikanta S, Ganda OP, Jackson RA, Gleason RE, Kaldany A, Garovoy MR, Milford EL, Carpenter CB, Soeldner JS, Eisenbarth GS. Type I diabetes mellitus in monozygotic twins: chronic progressive beta cell dysfunction. Annals of internal medicine. 1983; 99:320-326. [PubMed: 6351687]

16. Srikanta S, Ganda OP, Eisenbarth GS, Soeldner JS. Islet-cell antibodies and beta-cell function in monozygotic triplets and twins initially discordant for Type I diabetes mellitus. N Engl J Med. 1983; 308:322-325. [PubMed: 6337325]

17. Heaton DA, Lazarus NR, Pyke DA, Leslie RD. B-cell responses to intravenous glucose and glucagon in non-diabetic twins of patients with type 1 (insulin-dependent) diabetes mellitus. Diabetologia. 1989; 32:814-817. [PubMed: 2687066]

18. Lo SS, Hawa M, Beer SF, Pyke DA, Leslie RD. Altered islet beta-cell function before the onset of type 1 (insulin-dependent) diabetes mellitus. Diabetologia. 1992; 35:277-282. [PubMed: 1563585]

19. Barker JM, McFann K, Harrison LC, Fourlanos S, Krischer J, Cuthbertson D, Chase HP, Eisenbarth GS, Group DPTS. Pre-type 1 diabetes dysmetabolism: maximal sensitivity achieved with both oral and intravenous glucose tolerance testing. The Journal of pediatrics. 2007; 150:3136. e36. [PubMed: 17188609] 
20. Chaillous L, Rohmer V, Maugendre D, Lecomte P, Marechaud R, Marre M, Guilhem I, Charbonnel B, Sai P. Differential beta-cell response to glucose, glucagon, and arginine during progression to type I (insulin-dependent) diabetes mellitus. Metabolism: clinical and experimental. 1996; 45:306-314. [PubMed: 8606636]

21. Lupi R, Marselli L, Dionisi S, Del Guerra S, Boggi U, Del Chiaro M, Lencioni C, Bugliani M, Mosca F, Di Mario U, Del Prato S, Dotta F, Marchetti P. Improved insulin secretory function and reduced chemotactic properties after tissue culture of islets from type 1 diabetic patients. Diabetes Metab Res Rev. 2004; 20:246-251. [PubMed: 15133757]

22. Marchetti P, Dotta F, Ling Z, Lupi R, Del Guerra S, Santangelo C, Realacci M, Marselli L, Di Mario U, Navalesi R. Function of pancreatic islets isolated from a type 1 diabetic patient. Diabetes Care. 2000; 23:701-703. [PubMed: 10834434]

23. Eisenbarth GS. Type I diabetes mellitus. A chronic autoimmune disease. N Engl J Med. 1986; 314:1360-1368.

24 ••. Keenan HA, Sun JK, Levine J, Doria A, Aiello LP, Eisenbarth G, Bonner-Weir S, King GL. Residual insulin production and pancreatic ss-cell turnover after 50 years of diabetes: Joslin Medalist Study. Diabetes. 2010; 59:2846-2853. [PubMed: 20699420] Individuals with longstanding T1D (up to 17 years post-diagnosis) were subjected to an arginine stimulation test and a mixed-meal test. 55\% had measurable C-peptide in both tests while smaller cohorts exhibited release to only arginine $(12.5 \%)$ or mix-meal $(17.5 \%)$.

25. Liu EH, Digon BJ 3rd, Hirshberg B, Chang R, Wood BJ, Neeman Z, Kam A, Wesley RA, Polly SM, Hofmann RM, Rother KI, Harlan DM. Pancreatic beta cell function persists in many patients with chronic type 1 diabetes, but is not dramatically improved by prolonged immunosuppression and euglycaemia from a beta cell allograft. Diabetologia. 2009; 52:1369-1380. [PubMed: 19418039]

26. Rother KI, Spain LM, Wesley RA, Digon BJ 3rd, Baron A, Chen K, Nelson P, Dosch HM, Palmer JP, Brooks-Worrell B, Ring M, Harlan DM. Effects of exenatide alone and in combination with daclizumab on beta-cell function in long-standing type 1 diabetes. Diabetes care. 2009; 32:22512257. [PubMed: 19808924]

$27 \bullet$. Wang L, Lovejoy NF, Faustman DL. Persistence of prolonged C-peptide production in type 1 diabetes as measured with an ultrasensitive C-peptide assay. Diabetes care. 2012; 35:465-470. [PubMed: 22355018]

28. Oram RA, Jones AG, Besser RE, Knight BA, Shields BM, Brown RJ, Hattersley AT, McDonald TJ. The majority of patients with long-duration type 1 diabetes are insulin microsecretors and have functioning beta cells. Diabetologia. 2014; 57:187-191. [PubMed: 24121625]

29. Campbell-Thompson M, Wasserfall C, Kaddis J, Albanese-O’Neill A, Staeva T, Nierras C, Moraski J, Rowe P, Gianani R, Eisenbarth G, Crawford J, Schatz D, Pugliese A, Atkinson M. Network for Pancreatic Organ Donors with Diabetes (nPOD): developing a tissue biobank for type 1 diabetes. Diabetes/metabolism research and reviews. 2012; 28:608-617. [PubMed: 22585677]

30. Steele C, Hagopian WA, Gitelman S, Masharani U, Cavaghan M, Rother KI, Donaldson D, Harlan DM, Bluestone J, Herold KC. Insulin secretion in type 1 diabetes. Diabetes. 2004; 53:426-433. [PubMed: 14747294]

31. Sherr JL, Ghazi T, Wurtz A, Rink L, Herold KC. Characterization of residual beta cell function in long-standing type 1 diabetes. Diabetes/metabolism research and reviews. 2014; 30:154-162. [PubMed: 24115337]

32. Krogvold L, Edwin B, Buanes T, Ludvigsson J, Korsgren O, Hyoty H, Frisk G, Hanssen KF, DahlJorgensen K. Pancreatic biopsy by minimal tail resection in live adult patients at the onset of type 1 diabetes: experiences from the DiViD study. Diabetologia. 2014; 57:841-843. [PubMed: 24429579]

33. Atkinson MA. Pancreatic biopsies in type 1 diabetes: revisiting the myth of Pandora's box. Diabetologia. 2014; 57:656-659. [PubMed: 24442510]

34. Anderson MS, Bluestone JA. The NOD mouse: a model of immune dysregulation. Annual review of immunology. 2005; 23:447-485.

35. Ize-Ludlow D, Lightfoot YL, Parker M, Xue S, Wasserfall C, Haller MJ, Schatz D, Becker DJ, Atkinson MA, Mathews CE. Progressive erosion of beta-cell function precedes the onset of 
hyperglycemia in the NOD mouse model of type 1 diabetes. Diabetes. 2011; 60:2086-2091. [PubMed: 21659497]

36. Shimada A, Charlton B, Taylor-Edwards C, Fathman CG. Beta-cell destruction may be a late consequence of the autoimmune process in nonobese diabetic mice. Diabetes. 1996; 45:10631067. [PubMed: 8690153]

37. Chatenoud L, Thervet E, Primo J, Bach JF. Anti-CD3 antibody induces long-term remission of overt autoimmunity in nonobese diabetic mice. Proceedings of the National Academy of Sciences of the United States of America. 1994; 91:123-127. [PubMed: 8278351]

38. Parker MJ, Xue S, Alexander JJ, Wasserfall CH, Campbell-Thompson ML, Battaglia M, Gregori S, Mathews CE, Song S, Troutt M, Eisenbeis S, Williams J, Schatz DA, Haller MJ, Atkinson MA. Immune depletion with cellular mobilization imparts immunoregulation and reverses autoimmune diabetes in nonobese diabetic mice. Diabetes. 2009; 58:2277-2284. [PubMed: 19628781]

39. Sever D, Eldor R, Sadoun G, Amior L, Dubois D, Boitard C, Aflalo C, Melloul D. Evaluation of impaired beta-cell function in nonobese-diabetic (NOD) mouse model using bioluminescence imaging. FASEB journal : official publication of the Federation of American Societies for Experimental Biology. 2011; 25:676-684. [PubMed: 21118902]

40. Reddy S, Liu W, Thompson JM, Bibby NJ, Elliott RB. First phase insulin release in the non-obese diabetic mouse: correlation with insulitis, beta cell number and autoantibodies. Diabetes research and clinical practice. 1992; 17:17-25. [PubMed: 1511657]

41. Orban T, Sosenko JM, Cuthbertson D, Krischer JP, Skyler JS, Jackson R, Yu L, Palmer JP, Schatz D, Eisenbarth G, Diabetes Prevention Trial-Type 1 Study G. Pancreatic islet autoantibodies as predictors of type 1 diabetes in the Diabetes Prevention Trial-Type 1. Diabetes care. 2009; 32:2269-2274. [PubMed: 19741189] 

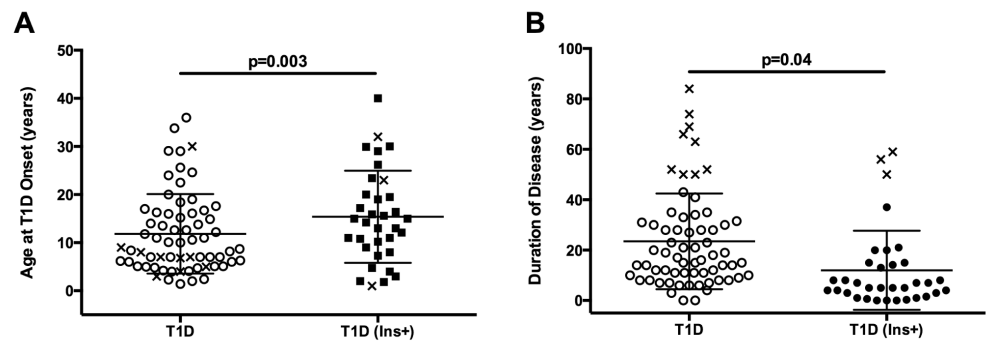

Figure 1.

nPOD cases with insulin positive islets have a later age of onset (A) and a shorter duration of disease (B) when compared to cases without insulin positive islets. This figure contains data from all of the cases within nPOD ( $n=100$ as of April 1, 2014) that are classified as donors with T1D ( $\mathrm{n}=88 ; 31$ had insulin positive islets by immunohistochemistry) and T1D Medalist ( $\mathrm{n}=12 ; 3$ had insulin positive islets by immunohistochemistry). T1D Medalists appear as an $\mathrm{X}$ in each graph. These publically available data were obtained from the nPOD Aperio Spectrum database (http://ahc-path-apr01.ahc.ufl.edu/). 